Témoigner Témoigner. Entre histoire et mémoire

Getuigen Revue pluridisciplinaire de la Fondation Auschwitz

$119 \mid 2014$

II y a 70 ans, Auschwitz. Retour sur Primo Levi

\title{
Babi Yar, témoignage extraordinaire par Kondrachine
}

Babi Yar, an exceptional testimony by Kondrachin

Babi Jar, een bijzondere getuigenis door Kondrasjin

Jean-Christophe Le Toquin

\section{(2) OpenEdition}

\section{Journals}

Édition électronique

URL : http://journals.openedition.org/temoigner/1594

DOI : $10.4000 /$ temoigner.1594

ISSN : 2506-6390

Éditeur :

Éditions du Centre d'études et de documentation Mémoire d'Auschwitz, Éditions Kimé

Édition imprimée

Date de publication : 31 décembre 2014

Pagination : $35-36$

ISBN : 978-2-84174-688-0

ISSN : 2031-4183

Référence électronique

Jean-Christophe Le Toquin, «Babi Yar, témoignage extraordinaire par Kondrachine », Témoigner. Entre

histoire et mémoire [En ligne], 119 | 2014, mis en ligne le 01 janvier 2016, consulté le 23 octobre 2020.

URL : http://journals.openedition.org/temoigner/1594; DOI : https://doi.org/10.4000/temoigner.1594

Tous droits réservés 


\section{BABI YAR, TEMOIGNAGE EXTRAORDINAIRE PAR KONDRACHINE}

DISQUE Qu'est-ce qu'un vrai Russe? À cette question particulièrement actuelle, à l'heure de la montée du sentiment national en Russie comme à travers toute l'Europe, Dimitri Chostakovitch répondait en 1962 en reprenant dans sa Symphonie $n^{\circ} 13$ "Babi Yar » les mots du poète Evgueni Evtouchenko: «II n'y a pas de sang juif dans mes veines, mais sur moi pèse la hideuse haine de tous les antisémites comme si jétais un Juif : et voilà pourquoi je suis un vrai Russe!»

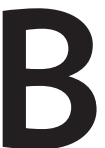

abi Yar, un ravin près de Kiev, fait partie des lieux de sinistre mémoire hérités des nazis. Le 29 septembre 1941, en rétorsion aux fortes pertes subies par les soldats allemands du fait d'incendies et d'explosions organisés par la résistance, les nazis y exterminèrent les Juifs de Kiev qui n'avaient pas encore fui la ville, soit 22000 victimes en une seule journée. Dans les mois qui suivirent et jusqu'en 1943, les massacres continuèrent touchant Ukrainiens, Polonais, Tziganes pour atteindre les 100000 victimes. En 1961, lorsque Evtouchenko fait paraître son poème, il n'existait sur les lieux de ces massacres aucune trace, aucun mémorial ou stèle, et les autorités soviétiques ne souhaitaient pas voir de commémoration de ces événements. Cette volonté d'oubli de la tragédie contre les populations, cette négation de la spécificité du crime commis contre les Juifs, n'étaient pas propre à l'URSS à l'époque. Toutefois, en URSS, elle était le résultat d'un antisémitisme d'État.

C'est dans ce contexte que Dimitri Chostakovitch choisit de témoigner et de faire de Babi Yar le premier mouvement de sa Symphonie $n^{\circ} 13$, l'année où il doit 
•• devenir membre du Soviet suprême. La Symphonie $n^{\circ} 12$ «1917 » était une concession aux exigences du régime soviétique, celle-ci est une critique en règle des crimes contre l'humanité (1. Babi Yar), de l'ambition professionnelle matérialiste obtenue au prix de la trahison de ses idéaux (5. Carriérisme), des peurs imposées par la dictature (4. Angoisses). Elle est aussi, en contrepoint, une apologie du courage des femmes (3. Au magasin) et de la force indomptable et corrosive de l'humour (2. Humour).

Les autorités n’apprécièrent pas que le poème de Babi Yar se concentre sur l'extermination des Juifs de Kiev, la doxa voulant que les victimes soient toutes soviétiques sans mention de nationalité. Faute d'obtenir la modification du texte, elles s'appliquèrent à perturber la création. Evgueni Mravinski qui devait assurer la création se décommanda, et Kirill Kondrachine assura la relève. La basse, qui tient un rôle crucial dans la symphonie, faisait partie de la troupe du Bolchoï et fut réquisitionnée à la dernière minute pour une représentation du Prince Igor. En dépit de ces épreuves, la création eut bien lieu le 18 décembre 1962 dans la Grande Salle du Conservatoire et la symphonie fut redonnée le 20 décembre, et enregistrée avec soin. C'est cet enregistrement qu'édite Praga Digitals, beaucoup plus rare que celui de 1967 pour Melodia avec le même chef et le même orchestre, mais avec un texte révisé conformément aux volontés des autorités.

La création d'une symphonie de Chostakovitch était un énorme événement dans la vie musicale de l'Union Soviétique, et écouter l'enregistrement de la création de sa symphonie la plus ouvertement polémique de tout son corpus orchestral est en soi une expérience historique de premier plan.

Les interprètes sont-ils artistiquementà la hauteur des circonstances et de la hauteur morale de l'œuvre? Absolument. La tension et l'émotion sont particulièrement palpables dans les premières mesures. Tout au long du premier mouvement, la basse Vitaly Gromadski porte une attention particulière à l'articulation du poème, pour que la salle n'en perde pas une syllabe. Passé l'ambiance de plomb de l'introduction, l'Orchestre philharmonique de Moscou et le chœur donnent tout ce qu'ils ont. Chauffés à blanc, ils font corps avec la musique, avec laquelle ils sont en totale osmose. Si la version de 1967 ne perd rien de sa force et reste une pierre angulaire de la discographie, cet enregistrement de 1962 a l'atout incomparable d'être un document artistique et politique. Par-dessus tout, il est le témoignage palpable, direct, d'hommes qui se dressent pour défendre la mémoire de ceux qui ont été exterminés parce qu'ils étaient pensés comme d'une autre race.

Au fait, pourquoi Chostakovitch s'intéressait-il au sort des Juifs au point de risquer une nouvelle fois sa carrière, lui qui avait été ostracisé sous Staline, d'abord, en 1936-1937 pour la modernité et l'érotisme de son opéra MacBeth de Mtsensk, puis de 1948 à 1953 et, enfin, pour ses symphonies trop tragiques (Symphonie $n^{\circ} 8$, 1943) ou trop guillerettes (Symphonie ${ }^{\circ}$ 9, 1945)? Irina Chostakovitch dans son entretien « Dimitri en son siècle » l'explique simplement : Chostakovitch comptait beaucoup d'amis juifs, musiciens ou non, et c'est pourquoi « la question juive était tellement douloureuse pour lui.» Quant au risque que Chostakovitch prenait pour lui-même et sa position de musicien en URSS, les dernières paroles de la symphonie apportent une réponse transparente à cette question: «Je fais une carrière en ne la faisant pas. » Au cimetière de Novodievitchié à Moscou, la tombe de Chostakovitch est ornée d'une discrète croix chrétienne.

À côté de ce monument d'humanité, les extraits de la gigantesque cantate Octobre de Sergueï Prokofiev composée en 1937 pour les 20 ans de la Révolution et créée seulement en 1966 par Kondrachine et son orchestre sont une vraie curiosité, mais la comparaison avec Babi Yar est cruelle. Saluons enfin le remarquable travail sur le son, qui donne toute sa présence et son impact à la diction de Vitali Gromadski dans Babi Yar et à l'orchestre de Kondrachine.

Jean-Christophe Le Toquin

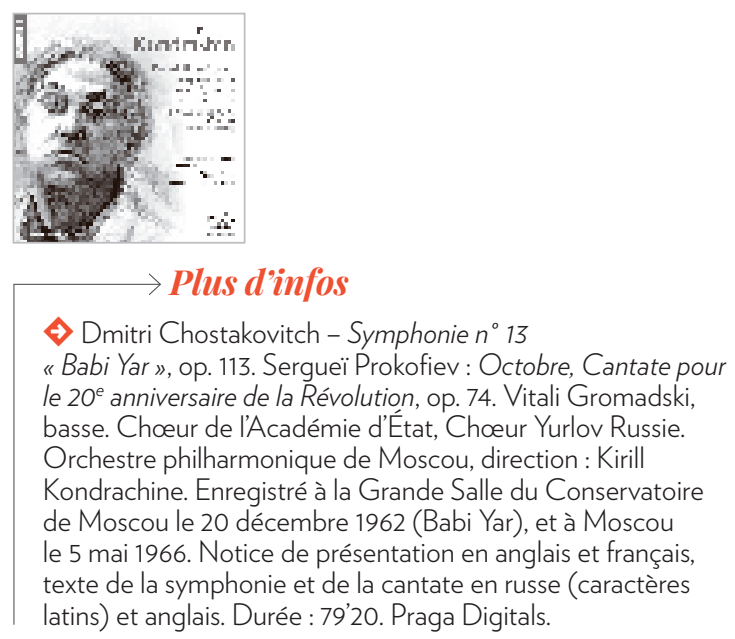

